\title{
The prevalence of determinants of obesity, metabolic syndrome and overweight in middle-aged urban women living in a megacity
}

\author{
ZAHRA ABBASPOOR ${ }^{1, A, D-F}$, MAHSA MIRYAN ${ }^{2, \text { A, B }}$, MOHAMAD HOSSEIN HAGHIGHI-ZADEH ${ }^{3, c, ~ D,}$ \\ ORCID ID: 0000-0001-8095-096X
}

HOMEIRA RASHIDI ${ }^{4, D}$, FROZAN SHARIFIPOOR ${ }^{1,5, D, E}$, REZA AMANI $^{6, A, E}$

${ }^{1}$ Department of Midwifery, Menopause Andropause Research Center, Ahvaz Jundishapur University of Medical Sciences, Ahvaz, Iran

${ }^{2}$ Student Research Committee, Ahvaz Jundishapur University of Medical Sciences; Department of Nutrition, School of Paramedicine, Ahvaz Jundishapur University of Medical Sciences, Ahvaz, Iran

Student Research Committee, Tabriz University of Medical Sciences; Nutrition Research Center, Faculty of Nutrition and Food Sciences, Tabriz University of Medical Sciences, Tabriz, Iran

${ }^{3}$ Department of Statistics, School of Public Health, Ahvaz Jundishapur University of Medical Sciences, Ahvaz, Iran

${ }^{4}$ Health Research Institute, Diabetes Research Center, Ahvaz Jundishapur University of Medical Sciences, Ahvaz, Iran

${ }^{5}$ Department of Midwifery, School of Nursing and Midwifery, Kermanshah University of Medical Sciences,

Kermanshah, Iran

${ }^{6}$ Food Security Research Center, Department of Clinical Nutrition, School of Nutrition and Food Science, Isfahan University of Medical Sciences, Isfahan, Iran

A - Study Design, B - Data Collection, C - Statistical Analysis, D - Data Interpretation, E - Manuscript Preparation, F - Literature Search, G - Funds Collection

Summary Background. Obesity is a major health problem that can lead to chronic illness.

Objectives. The aim of this study was to determine the prevalence of determinants of obesity and overweight in middle-aged women in the city of Ahvaz.

Material and methods. This cross-sectional study was carried out on 600 urban women between 30-65 years of age that were invited to the Health Centres of Ahvaz, Iran, from April to November 2018. A randomised, multi-stage cluster sampling was used, and data was collected using demographic information, a Food Frequency Questionnaire (FFQ) and an International Physical Activity Questionnaire (IPAQ). General obesity was considered as a body mass index (BMI) $\geq 30 \mathrm{~kg} / \mathrm{m}^{2}$.

Results. The mean age of participants was $38.9 \pm 8$ years of age. In total, $73 \%$ were overweight and/or obese. The incidence of obesity was higher with illiterate, housewives and older women $(p<0.05)$. Obesity had a significant positive correlation with family size, the number of obese persons in the family and quantity of daily snacks $(p<0.05)$, as well as a reverse correlation with consuming oral contraceptive. There was relationship between BMI and consumption of red meat, fast food and snacks $(p<0.05)$, although in the general score of the food frequency questionnaire, the relations were not significant.

Conclusions. Prevention education programmes for achieving higher education, lesser family dimension, changes in lifestyle, including having a healthier nutritional diet, consuming the less fast food and red meat and more fruits and vegetables are recommended. Key words: obesity, overweight, women, feeding behaviour, exercise.

Abbaspoor Z, Miryan M, Haghighi-Zadeh MH, Rashidi H, Sharifipoor F, Amani R. The prevalence of determinants of obesity, metabolic syndrome and overweight in middle-aged urban women living in a megacity. Fam Med Prim Care Rev 2020; 22(1): 7-12, doi: https:// doi.org/10.5114/fmpcr.2020.92499.

\section{Background}

Obesity is one of the most important public health problems in the world as a concern of the health care community due to its growing prevalence [1]. The World Health Organization (WHO) in 2016 reported that over 1.9 billion adults were overweight. Of these, over 650 million were obese (BMI $\geq 30)$ worldwide. The prevalence of obesity in Iranian women is estimated to be $26.53 \%$. Although obesity was regarded as only a problem of high-income countries in the past, overweight and obesity are currently increasing in low- and middle-income countries, especially in urban areas [2]. Obesity is associated with many complications, including cardiovascular disease (CVD), type 2 diabetes, risk of certain cancers (uterus, breast and colon), hypertension, stroke, sleep apnoea, respiratory disease, lipid disorders, reproductive disorders and osteoarthritis [3]. Some studies have shown that abdominal fat is more likely to be a more promising predictor of breast cancer after menopause than general obesity [4]. Obesity and overweight have a direct correlation with weight gain, short duration of physical activity and different nutritional habits [5]. Damirchi and Mehrabani reported that with increasing age, the incidence of obesity increases [6]. Women are at increased risk of metabolic syndrome and CVD due to lower physical activity, different socioeconomic status, age, multiparity, hormonal changes and dietary habits [7].

Weight gain and increased waist circumference start before menopause and have a major impact on CVD in older women [8]. 
In addition to menopause, other risk factors can cause central obesity. These factors include non-regular physical activity, smoking and alcohol consuming and medications, especially insulin [9]. Research shows that middle-aged and elderly women with good physical activity have less whole-body fat and abdominal fat than low active women during their lifetime [10]. The consumption of fatty and sweet foods that are lacking in fibre and nutrients, as well as a lack of consuming fresh fruit and vegetables, is also associated with an increased incidence of obesity, diabetes, metabolic syndrome and CVDs [11]. The findings of a study by Sotoudeh et al. on 610 menopausal and non-menopausal women in Islamshar city, Iran, showed that the prevalence of overweight was $90.6 \%$ and $72.6 \%$ in menopausal and non-menopausal women, and the prevalence of obesity was $75 \%$ and $41.9 \%$, respectively [12]. The results of a study in European countries showed that obese and overweight groups were more likely to be unemployed, be more cigarettes' smoker, less educated, less general health, lower social participation and less free time to do physical activity than those with normal weight [13]. In a study by Jagielska et al. in Poland, anthropometric measurements of patients after liver transplant revealed an impaired nutritional status, including metabolic obesity, and the physical level of activity was insufficient [14].

In many countries in the Asian region, as well as in Iran, there are increasing trends toward changes in dietary behaviour, such as eating outside, consumption of fried foods and additional use of snacks. Overeating is a concern among some people, especially women [15]. Due to the high prevalence of obesity and its significant role in the development of metabolic disorders, the importance of controllable factors, such as nutritional habits and physical activity, in the onset of this disease is obvious.

\section{Objectives}

This study aimed to determine the prevalence of determinants of obesity and overweight in middle-aged urban women living in a megacity.

\section{Material and methods}

\section{Design and subjects}

This cross-sectional study was conducted on 600 women 30-65 years of age referred to Ahvaz health centres in Iran from April to November 2018. The criteria for entering the study included: aged 30 to 65 , at least 6 months have passed since the last menstruation, having at least reading and writing skills and willingness to participate. Exclusion criteria included: any known disease (hypothyroidism, polycystic ovarian syndrome and Cushing's syndrome) and pregnancy with a duration $>3$ months. According to a study by Kelishadi et al. [16], with a mean proportion of $p=0.5$ and a confidence level of $95 \%$, a sample size of 600 was obtained based on the following formula:

$$
n=\frac{(1.96)^{2}(0.5)(0.5)}{(0.04)^{2}}=600 .
$$

Sampling was done according to the multi-stage cluster method. The middle-aged women were selected according to the estimated sample size, and 25 health centres were randomly selected from the eastern and western areas of the city.

In each health centre, 4 recorded family files were randomly selected as a cluster. Afterwards, 6 neighbouring households were selected as clusters, and a total of 100 clusters were chosen from 25 centres. Referring to the family files, if there was a middle-aged woman in the family having the inclusion criteria, she was invited to attend the centre by phone call or through health provider volunteers. In the absence of a middle-aged woman in that family, neighbouring households were used to replace the samples, and sampling continued to find 6 middle-aged women in each cluster, i.e. from each centre, $4 \times 6=24$ middle-aged women, and a total of $24 \times 25=600$ women were studied. After obtaining the approval of the Ethics Committee and written consent and briefing women about the goals of the study, as well as confidentiality assurance, they completed the demographic information, physical activity and nutrition questionnaire through interviews. Anthropometric measurements, including height, weight and body fat percentage measurements, were also recorded.

\section{Measurements}

The data gathering tools included: demographic information questionnaire, FFQ and IPAQ questionnaires.

The FFQ is the most appropriate and most effective method for evaluating diet, and its validity and reliability were confirmed in a semi-quantitative manner on the basis of food consumption in the last year by Mameghani et al., based on factor analysis and the interpretation of food items in each factor, in which three factors were introduced as healthy, Western and traditional dietary patterns [17]. In this study, an adjusted short form of an 86-item FFQ, in which validity and reliability were re-assessed by the Department of Nutrition at Ahvaz University of Medical Sciences, was used. This questionnaire consisted of 86 food items based on consumed food groups during the last six months. The optional answers were as: "I do not eat", "Daily", "Weekly" and "Monthly" intake. To equalise responses, the frequency of food intake during the week or month was converted to daily intake, and the daily intake of food items for each individual was determined [18]. Validity and reliability of the questionnaire were confirmed by experts, as well as in previous studies with an acceptable coefficient (Cronbach's alpha, 0.82). IPAQ includes questions about physical activity related to work, travel, chores and leisure time during the past 7 days. Total MET was calculated for the grouping of the subjects according to the instructions of the questionnaire. Thus, if the combination of moderate, severe or light (walking) activities in the past 7 days was less than 600 Met-min/week, it was considered as low physical activity, between 600 and 3,000 Met-min/week was considered as moderate physical activity, and if there was more than 3,000 Met-min/week, it was considered as severe physical activity [19]. This tool was developed by an international expert group in Geneva in 1998, and its validity and reliability are confirmed in 12 countries [20]. The weight was measured with minimum clothing and no shoes and recorded using the Seca Digital Scale (Germany), with a precision of $100 \mathrm{~g}$. Height was measured using a tape measure in a standing position beside a wall without shoes, with the head, shoulders, heel and buttocks in contact with the wall, with a precision of one millimetre. BMI was calculated by dividing the weight $(\mathrm{kg})$ with the squared height $\left(\mathrm{m}^{2}\right)$. Obesity and overweight were evaluated based on WHO standard criteria. Obesity was defined as a BMI $\geq 30$; overweight as BMI: 25-29.9, and underweight was defined as $\mathrm{BMI}<18.5 \mathrm{~kg} / \mathrm{m}^{2}$. Waist circumference was measured using tape measures, with a $0.1 \mathrm{~cm}$ accurately. Abdominal obesity was defined according to the WHO criteria for waist to hip ratio $(W H R>0.8 \mathrm{~cm})$ [21]. Body fat percent $(\mathrm{BF} \%)$ was measured via the bio impedance method using an Omron BF 511 set.

\section{Statistics}

Data was analysed with SPSS software version 22 using independent $t$-test, chi-square, ANOVA and Pearson's and Spearman's correlation coefficient tests.

\section{Results}

The frequency of obesity was $36.5 \%$, overweight was $36.5 \%$, and $27.1 \%$ of the participants had normal BMI. The mean age of women was $38.9 \pm 8$ years. The demographic information is shown in Table 1. 


\begin{tabular}{|c|c|c|c|c|}
\hline Variables & $\begin{array}{l}\text { Normal weight } \\
n=164(27.1 \%)\end{array}$ & $\begin{array}{l}\text { Overweight } \\
n=218 \text { (36.5\%) }\end{array}$ & $\begin{array}{l}\text { Obese } \\
n=218 \text { (36.5\%) }\end{array}$ & $p$ \\
\hline & Mean \pm SD; N (\%) & & & \\
\hline Age & $36.64 \pm 7.1$ & $38.95 \pm 8.78$ & 40.99 & $p=0.000 *$ \\
\hline Marriage age & $22.51 \pm 4.5$ & $20.3 \pm 4.6$ & 19.65 & $p=0.082^{*}$ \\
\hline Menopausal age & $48.88 \pm 2.05$ & $49.26 \pm 2.77$ & 47.98 & $p=0.074^{*}$ \\
\hline $\begin{array}{l}\text { Economic status } \\
\text { very good } \\
\text { good } \\
\text { medium } \\
\text { bad } \\
\end{array}$ & $\begin{array}{l}6(3.7) \\
58(35.4) \\
82(50) \\
18(10.9) \\
\end{array}$ & $\begin{array}{l}9(4.1) \\
95(43.6) \\
90(41.3) \\
24(11.0)\end{array}$ & $\begin{array}{l}12(5.5) \\
67(30.7) \\
110(50.5) \\
29(13.3) \\
\end{array}$ & $p=0.089 * *$ \\
\hline $\begin{array}{l}\text { Accommodation state } \\
\text { owner } \\
\text { leasing } \\
\text { lives with family } \\
\text { governmental home }\end{array}$ & $\begin{array}{l}81(49.9) \\
58(35.4) \\
21(12.8) \\
4(2.4)\end{array}$ & $\begin{array}{l}123(56.4) \\
72(33) \\
16(7.3) \\
7(3.2) \\
\end{array}$ & $\begin{array}{l}102(46.8) \\
67(30.7) \\
35(16.1) \\
14(6.4)\end{array}$ & $p=0.29 * *$ \\
\hline $\begin{array}{l}\text { Family dimensions } \\
\qquad \begin{array}{l}1-4 \\
5-10 \\
>10\end{array}\end{array}$ & $\begin{array}{l}13(68.9) \\
49(29.9) \\
2(1.2) \\
\end{array}$ & $\begin{array}{l}139(63.8) \\
77(35.3) \\
2(0.9) \\
\end{array}$ & $\begin{array}{l}107(49.1) \\
101(46.3) \\
10(4.6) \\
\end{array}$ & $p=0.000^{* *}$ \\
\hline $\begin{array}{l}\text { Using OCP } \\
\text { no } \\
\text { yes }\end{array}$ & $\begin{array}{l}119(72.6) \\
45(27.4)\end{array}$ & $\begin{array}{l}189(86.7) \\
29(13.3)\end{array}$ & $\begin{array}{l}179(82.1) \\
39(17.9)\end{array}$ & $p=0.002 * *$ \\
\hline $\begin{array}{l}\text { General health state } \\
\text { very bad } \\
\text { bad } \\
\text { sometimes bad } \\
\text { normal } \\
\text { sometimes good } \\
\text { good } \\
\text { very good } \\
\end{array}$ & $\begin{array}{l}2(1.2) \\
6(3.7) \\
24(14.6) \\
94(57.3) \\
12(7.3) \\
21(12.8) \\
5(3) \\
\end{array}$ & $\begin{array}{l}2(0.9) \\
24(11) \\
37(17) \\
129(59.9) \\
11(5) \\
15(6.9) \\
0 \\
\end{array}$ & $\begin{array}{l}5(2.3) \\
11(5) \\
64(29.4) \\
105(48.2) \\
15(6.9) \\
18(8.3) \\
0 \\
\end{array}$ & $p=0.07^{* *}$ \\
\hline $\begin{array}{l}\text { Obesity in the family } \\
\text { nil } \\
1 \\
2\end{array}$ & $\begin{array}{l}105(64) \\
57(34.8) \\
2(1.2) \\
\end{array}$ & $\begin{array}{l}125(57.3) \\
92(42.2) \\
1(0.5) \\
\end{array}$ & $\begin{array}{l}93(42.7) \\
125(57.3) \\
0\end{array}$ & $p=0.000^{* *}$ \\
\hline $\begin{array}{l}\text { No. of meals/day } \\
1-3 \\
\text { more than } 3\end{array}$ & $\begin{array}{l}128(78) \\
36(22)\end{array}$ & $\begin{array}{l}178(81.7) \\
40(18.3)\end{array}$ & $\begin{array}{l}180(82.6) \\
38(17.4)\end{array}$ & $p=0.513^{* *}$ \\
\hline $\begin{array}{l}\text { Number of snacks/day } \\
0 \\
1-3 \\
\text { more than } 3\end{array}$ & $\begin{array}{l}4(2.5) \\
105(60.4) \\
54(33.1) \\
\end{array}$ & $\begin{array}{l}0 \\
121(55.5) \\
97(44.5) \\
\end{array}$ & $\begin{array}{l}0 \\
141(64.7) \\
77(35.3) \\
\end{array}$ & $p=0.003^{* *}$ \\
\hline $\begin{array}{l}\text { Ethnic group } \\
\text { Fars } \\
\text { Arab } \\
\end{array}$ & $\begin{array}{l}106(64.7) \\
58(35.4)\end{array}$ & $\begin{array}{l}126(57.9) \\
92(42.2)\end{array}$ & $\begin{array}{l}135(60.0) \\
83(38.1)\end{array}$ & $p=0.041 * *$ \\
\hline $\begin{array}{l}\text { Literacy level } \\
\text { primary school } \\
\text { secondary school } \\
\text { diploma } \\
\text { university graduate }\end{array}$ & $\begin{array}{l}21(12.8) \\
19(11.6) \\
48(29.3) \\
76(46.3)\end{array}$ & $\begin{array}{l}35(16.1) \\
59(27.1) \\
69(31.7) \\
55(25.2)\end{array}$ & $\begin{array}{l}61(28) \\
76(34.9) \\
54(24.8) \\
27(12.4)\end{array}$ & $p=0.000 * *$ \\
\hline $\begin{array}{l}\text { Employment } \\
\text { housewife } \\
\text { worker } \\
\text { clerk } \\
\text { self employed } \\
\text { other }\end{array}$ & $\begin{array}{l}100(61) \\
0 \\
46(28) \\
6(3.7) \\
12(7.3)\end{array}$ & $\begin{array}{l}161(73.9) \\
8(3.7) \\
40(18.3) \\
5(2.3) \\
4(1.8)\end{array}$ & $\begin{array}{l}189(86.7) \\
14(6.4) \\
8(3.7) \\
4(1.8) \\
3(1.4)\end{array}$ & $p=0.000 * *$ \\
\hline
\end{tabular}

* ANOVA; ${ }^{* *}$ chi-square test.

Marital and menopausal age was not different between the three groups of BMI. Economic status and number of meals per day did not show any significant differences in the three groups. There were significant differences in the family dimension between the three groups $(p<0.05)$, with $46.3 \%$ of obese women having a family size of 5-10 members. Using OCP, physical condition and general health, presence of obese persons in the family, consum- ing daily snacks, ethnicity, education and occupational status were significantly different in the three groups $(p<0.05)$, with the obese $\mathrm{BMI}$ group compared to the overweight group using more OCPs. In terms of physical activity, most women who had light physical activity were overweight (48.2\%). The normal BMI group showed a better general health status and a higher educational level $(p<0.05)$. Most women in the three BMI groups were housewives. 


\begin{tabular}{|c|c|c|c|c|}
\hline \multirow[t]{2}{*}{ Variables } & $\begin{array}{l}\text { Normal } \\
n=164\end{array}$ & $\begin{array}{l}\text { Overweight } \\
n=218\end{array}$ & $\begin{array}{l}\text { Obese } \\
n=218 \\
\end{array}$ & \multirow[t]{2}{*}{$p^{*}$} \\
\hline & \multicolumn{3}{|l|}{ Mean \pm SD } & \\
\hline Oils and sweets ${ }^{a}$ & $150.67 \pm 76.15$ & $166.93 \pm 75.45$ & $177.64 \pm 87.45$ & $p=0.005$ \\
\hline Fruits $^{\mathrm{b}}$ & $19.86 \pm 20.1$ & $25.85 \pm 22.23$ & $22.67 \pm 21.54$ & $p=0.025$ \\
\hline Vegetables ${ }^{\mathrm{c}}$ & $25.91 \pm 23.73$ & $35.56 \pm 29.08$ & $35.66 \pm 35.004$ & $p=0.001$ \\
\hline Meat $^{d}$ & $45.08 \pm 40.08$ & $51.28 \pm 54.53$ & $37.49 \pm 25.35$ & $p=0.003$ \\
\hline Dairy products ${ }^{\mathrm{e}}$ & $38.89 \pm 30.09$ & $32.37 \pm 28.94$ & $36.63 \pm 31.43$ & $p=0.097$ \\
\hline Bread and cereals ${ }^{f}$ & $63.09 \pm 40.40$ & $64.54 \pm 42.96$ & $58.81 \pm 35.5$ & $p=0.298$ \\
\hline
\end{tabular}

a Cakes and cookies, fast food, snacks, butter and margarine, soft drinks, sweets, sugar, cream, olive oil, hydrogenated oils and non-hydrogenated oils; ${ }^{b}$ fresh fruits and natural juices; ${ }^{c}$ salad, raw and cooked vegetables; ${ }^{d}$ eggs, meat, visceral meet, chicken, fish, shrimp; ${ }^{\mathrm{e}}$ low-fat and high-fat dairy; ${ }^{f}$ complete bread and cereals, refined grains and potatoes; SD - standard deviation; * ANOVA test.

\begin{tabular}{|l|l|l|l|l|}
\hline Table 3. Physical activity levels and energy expenditure in BMI groups based on IPAQ \\
\hline Physical activity & $\begin{array}{l}\text { Normal } \\
n=164\end{array}$ & $\begin{array}{l}\text { Over } \\
n=218\end{array}$ & $\begin{array}{l}\text { Obese } \\
n=218\end{array}$ & \multirow{2}{*}{} \\
\cline { 2 - 4 } & $n(\%)$ & $105(48.2)$ & $65(39.6)$ & $p=0.271$ \\
\hline Light activity & $99(45.4)$ & $78(35.8)$ & $68(41.5)$ & \\
\hline Moderate activity & $72(33.0)$ & $35(16.1)$ & $31(18.9)$ & \\
\hline Severe activity & $47(21.6)$ & $1727(8417)$ & $1948(0518)$ & $* * p=0.251$ \\
\hline Energy expenditure per week (Calorie) (min/week) & $2238(4518)$ & & & \\
\hline
\end{tabular}

* Chi-square test; ** ANOVA test.

\begin{tabular}{|c|c|c|c|c|}
\hline Variable & $r$ & $p$ & $r$ & $p$ \\
\hline $\begin{array}{l}\text { Age } \\
\text { menopausal age } \\
\text { ethnicity } \\
\text { accommodation state } \\
\text { using ocp } \\
\text { general health }\end{array}$ & $\begin{array}{l}0.237^{* *} \\
-0.153 \\
0.071 \\
0.058 \\
0.082^{*} \\
-0.143^{* *}\end{array}$ & $\begin{array}{l}<0.001 \\
0.134 \\
0.083 \\
0.155 \\
0.044 \\
<0.001\end{array}$ & $\begin{array}{l}0.077 \\
0.002 \\
0.078 \\
-0.054 \\
0.098 * * \\
-0.124 * *\end{array}$ & $\begin{array}{l}0.058 \\
0.988 \\
0.055 \\
0.189 \\
0.016 \\
0.002\end{array}$ \\
\hline $\begin{array}{l}\text { Intake food groups } \\
\text { oils and sweets } \\
\text { fruits } \\
\text { vegetables } \\
\text { meat } \\
\text { dairy } \\
\text { bread and cereals }\end{array}$ & $\begin{array}{l}-0.150^{* *} \\
0.024 \\
0.081^{*} \\
-0.037 \\
-0.034 \\
-0.027 \\
\end{array}$ & $\begin{array}{l}<0.001 \\
0.560 \\
0.048 \\
0.370 \\
0.407 \\
0.506\end{array}$ & $\begin{array}{l}0.064 \\
-0.179 * * \\
-0.124 * * \\
0.22 \\
0.03 \\
0.017 \\
\end{array}$ & $\begin{array}{l}0.115 \\
<0.001 \\
0.002 \\
0.592 \\
0.458 \\
0.674\end{array}$ \\
\hline $\begin{array}{l}\text { Physical activity level } \\
\text { light } \\
\text { moderate } \\
\text { severe }\end{array}$ & $\begin{array}{l}-0.042 \\
-0.016 \\
0.004\end{array}$ & $\begin{array}{l}0.307 \\
0.699 \\
0.923\end{array}$ & $\begin{array}{l}0.07 \\
0.055 \\
-0.057\end{array}$ & $\begin{array}{l}0.088 \\
0.182 \\
0.164 \\
\end{array}$ \\
\hline
\end{tabular}

$* p<0.05 ; * *<0.01$.

There were significant differences between the three groups of BMI in terms of nutritional habits, including consumption of oils and sweets, meat, vegetables and fruits $(p<0.05)$; however, this was not the same for the dairy, bread and cereal groups. Consumption of foods on the top of the food pyramid was higher in the obese and overweight groups (Table 2).

However, the mean score of IPAQ was not significantly different between the three groups (Table 3).

The relationship between age and BMI was positive $(r=0.24$, $p<0.001)$. Moreover, a positive correlation between taking OCP with BMI $(r=0.082, p=0.044)$ and WHR $(r=0.098, p=0.016)$ was witnessed. Furthermore, the correlation between general health and BMI $(r=-0.143, p<0.001)$ and WHR $(r=-0.124, p=$ 0.002 ) was significant. There was also a significant negative correlation between the consumption of oils and sweets with BMI ( $r=-0.150, p<0.001)$ and a negative correlation between fruits and vegetables with WHR, respectively $(r=-0.179, p<0.001$ and $r=-0.124, p=0.002)$. There was no significant relationship between BMI and consumption of other food groups (Table 4).

\section{Discussion}

In the present study, the relationship between some important demographics, nutritional pattern and physical activity level with overweight and obesity was studied in a population of middle-aged women in an urban megacity. The findings showed that $73 \%$ of the population aged $30-65$ years old was overweight and/or obese (both $36.5 \%$ ). The prevalence of overweight and obesity was lower than that of women in the city of Islam Shahr [15] and the Tehran province [22]. The prevalence of obesity in American women was reported as 35.8\% [23], and in Japanese women, this was $17.4 \%$ [24], which are less than the prevalence of obesity in Ahvazian women. In Canada, 62\% of 
adults are above normal weight, and 1 in 4 is obese [25]. The differences can partly be related to different sampling, age range and survey method, as well as demographic, economic and lifestyle differences. The results also showed that BMI significantly increases with age and daily snack consumption, which is consistent with the results of a study by Mazlooumzadeh et al., in which there was a significant positive relation between overweight/obesity with gender and age [26]. In the present study, as the dimension of the family increased, the prevalence of obesity was elevated, i.e. $68.9 \%$ of women with normal BMI had a family dimension of 1 to 4 , while about half of obese women came from a family of more than 5 members. These findings are in line with the study by Mohammadi et al., which showed a relationship between BMI and family dimension [27].

There was an inverse relation between overweight and obesity with educational level. In adult Japanese women, a lower education level was positively associated with being overweight and obese (OR 1.67 for overweight and OR 2.66 for obese women [28]), which could be due to the high level of awareness, nutritional knowledge and a healthier lifestyle in educated people.

In Sweden, obese and overweight groups were also less educated than the group of normal weight [13]. There was also a significant relationship between employment and BMI; housewives had higher BMI than employed women. This could be due to the lower level of education for housewives. The results of Sotoudeh et al. showed that women with a lower level of education and housewives had higher BMI [12]. In Sweden, obese and overweight people were also more likely to be unemployed [13].

The study of Motlagh et al. that assessed the BMI of 5 ethnic groups of Iranian students and its relationship with some personal and familial variables showed that the highest rates of overweight and obesity were seen among the Arab tribes, and the lowest was in the Sistani ethnic group. In our study, the highest rate of overweight and obesity were observed in the Fars ethnic group, which did not coincide with the Motlagh et al. study [29]. This discordance may be due to the fact that more Arabian women were housewives and had more activity than Fars people.

We also showed that an increase in the number of obese people in the family elevated the incidence of obesity, i.e. more than half of obese women had obese individuals in their family, which was comparable to a study by Watanabe et al. that showed that to prevent children's overweight/obesity, there should be a focus on shaping some behaviours in family environments, including regular mealtimes that need to be targeted among family members [30].

We found no significant correlation between BMI and physical activity level. However, Abdollahi et al. showed a high rate of obesity and overweight in women that were not engaged in any physical activity programmes $(82.7 \%)$ or those who exercises less than 2 hours a week (35.1\%) [31]. In another study, the amount of physical activity was seen as important in reducing metabolic syndrome risk in older adults with obesity [32]. In a study in Poland, patients after a liver transplant showed an insufficient level of physical activity [14].

There was also a significant negative correlation between the consumption of oils and sweets with $\mathrm{BMI}$ and a negative correlation between fruits and vegetables with WHR. Another study reported that obesity and overweight have a direct correlation with weight gain and different nutritional habits [5].

\section{Strengths and limitations of the study}

The strength of the study was the size of the study group; however, because of the wide range of women aged from 30 to 65 years and also because of the high cost, blood tests for hormonal abnormalities of obesity were not performed.

\section{Conclusions}

Considering a high rate of obesity and overweight and their determinants as nutritional habits, employment and educational level, providing and implementing educational programmes for promoting a healthier lifestyle for women, including nutritional habits to limit the consumption of fast food, red meat and bread and increasing the consumption of fruits, vegetables and dairy products, are recommended.

Acknowledgments. This paper was one part of a research project registered under No. MARC-9408 and ethical code number IR.AJUMS.REC.1394.739. Financial support was provided by the Vice-Chancellor for Research at Ahvaz Jundishapur University of Medical Sciences. We would like to thank all the participants.

Source of funding: This work was funded by the Ahvaz Jundishapur University of Medical Sciences.

Conflicts of interest: The authors declare no conflicts of interest.

\section{References}

1. Goel R, Agarwal A, Shabbir A, et al. Bariatric surgery in Singapore from 2005 to 2009. Asian J Surg 2013; 36(1): 36-39.

2. Obesity and overweight [cited 1.10.2017]. Available from URL: https://www.who.int/news-room/fact-sheets/detail/obesity-and-overweight.2016.

3. Ford ES, Maynard LM, Li C. Trends in mean waist circumference and abdominal obesity among US adults, 1999-2012. JAMA 2014; 312(11): 1151-1153.

4. Morimoto LM, White E, Chen Z, et al. Abdominal obesity: role in the pathophysiology of metabolic disease and cardiovascular risk. Am $J$ Med 2007; 120(2): S3-S8.

5. John M, Jakicic JM, Rogers RJ, et al. Role of physical activity and exercise in treating patients with overweight and obesity. Clinical Chemistry 2018; 64(1): 99-107.

6. Damirchi A, Mehrabani J. [Prevalence of obesity, overweight and hypertension and related riskfactors in adult men]. Olympic 2009; 47: 87-103 [in Persian].

7. Samiee RF, Ziaee A, Qambarian A, et al. [Association between risk factors of cardiovascular diseases and obesity among Tehranian women: Tehran Lipid and Glucose Study (TLGS)]. Iran J Endocrinol Metab 2012; 14(2): 101-108 103 [in Persian].

8. Elffers TW, de Mutsert R, Lamb HJ, et al. Body fat distribution, in particular visceral fat, is associated with cardiometabolic risk factors in obese women. PLOS ONE 2017; 12(9): e0185403, doi: 10.1371/journal.pone.0185403.

9. Artanti KD, Martini S, eds. Metabolic syndrome risk factors in employees faculty of public health, Universitas Airlangga. ICOPH 2017; 3(2): 128-133.

10. Pelclová J, Gába A, Tlučáková L, et al. Association between physical activity (PA) guidelines and body composition variables in middleaged and older women. Arch Gerontol Geriatr 2012; 55(2): e14-e20.

11. Mcleod ER, Campbell KJ. Nutrition knowledge: a mediator between socioeconomic position and diet quality in Australian first-time mothers. J Am Diet Assoc 2011; 111: 696-704. 
12. Sotoudeh G, Niyazi E, Khsravi S, et al. Prevalence and determinants of obesity and overweight in pre and post-menopausal women in Islamshahr: a population-based study. Hayat 2010: 16(2): 47-54.

13. Gallus S, Lugo A, Murisic B, et al. Overweight and obesity in 16 European countries. Eur J Nutr 2015; 54(5): 679-689.

14. Jagielska A, Jankowski K, Okręglicka K, et al. Lifestyle risk factors of non-communicable diseases among patients after liver transplantation - a pilot study. Fam Med Prim Care Rev 2017; 19(3): 214-220.

15. Fan JG, Kim SU, Wong VWS. New trends on obesity and NAFLD in Asia. J Hepatol 2017; 67(4): 862-873.

16. Kelishadi R, Alikhani S, Delavari A, et al. Obesity and associated lifestyle behaviors in Iran: findings from the first national non-communicable disease risk factor surveillance survey. Public Health Nutr 2008; 11(3): 246-251.

17. Mameghani M, Fared-Mogaddam A, Jafarabadi M. [Assessing the reliability and reproducibility of food frequency questionnaire and identify major dietary patterns in overweight and obese adults in Tabriz, Iran]. J Mazand Univ Med Sci 2014; 23(Suppl. 2): $46-57$ [in Persian].

18. Veissi M, Anari A, Amani R, et al. Mediterranean diet and metabolic syndrome prevalence in type 2 diabetes patients in Ahvaz, southwest of Iran. Diabetes Metab Syndr 2016; 10: S26-S29.

19. Fesharaki MG, Azad E. [Evaluation of the reliability and validity of Azad-Fesharaki's physical activity questionnaire (AFPAQ)]. Arak Medical University Journal 2011; 14(56): 36-44.

20. Vanneman A, Hamilton L, Anderson JB, et al. Achievement Gaps: How Black and White Students in Public Schools Perform in Mathematics and Reading on the National Assessment of Educational Progress. Statistical Analysis Report. NCES 2009-455. Available from URL: https://nces.ed.gov/nationsreportcard/pdf/studies/2009455.pdf.

21. Bauman A, Ainsworth BE, Sallis JF, et al. The descriptive epidemiology of sitting: a 20-country comparison using the International Physical Activity Questionnaire (IPAQ). Am J Prev Med 2011; 41(2): 228-235.

22. Moghimi-Dehkordi B, Safaee A, Vahedi M, et al. The prevalence of obesity and its associated demographic factors in Tehran, Iran. Journal of Health and Development 2012; 1(1): 22-30.

23. Flegal KM, Carroll MD, Kit BK, et al. Prevalence of obesity and trends in the distribution of body mass index among US adults, 1999-2010. JAMA 2012; 307(5): 47-91.

24. Tanaka S, Kuroda T, Saito M, et al. Overweight/obesity and underweight are both risk factors for osteoporotic fractures at different sites in Japanese postmenopausal women. Osteoporos Int 2013; 24(1): 69-76.

25. Shields M, Carroll MD, Ogden CL. Adult obesity prevalence in Canada and the United States. NCHS Data Brief 2011; 56: 1-8.

26. Mazlooumzadeh SM, Mousavi Viyeri A, Dinmohammadi H. [Epidemiology of overweight and obesity in Zanjan provience]. ZUMS Journal 2006; 14(56): 57-64 [in Persian].

27. Nakamura T, Nakamura Y, Saitoh S, et al. Relationship between socioeconomic status and the prevalence of underweight, overweight or obesity in a General Japanese Population: NIPPON DATA2010. J Epidemiol 2018; 28(Suppl. 3): S10-S16.

28. Mohammadi N, Shobyri F, Kheirallhe A, et al. Prevalence of overweight and obesity in women referred to health centers in Hamadan. Avicenna J Nurs Midfery Care 2011; 19(2): 36-46.

29. Motlagh M, Taheri M, Tahmasby B, et al. [BMI of Students in five ethnic groups in iran and its relationship with some demographic and familial variables]. J Mazandaran Univ Med Sci 2017; 27(155): 163-169 [in Persian].

30. Watanabe E, Lee JS, Mori K, et al. Clustering patterns of obesity-related multiple lifestyle behaviours and their associations with overweight and family environments: a cross-sectional study in Japanese preschool children. BMJ 2016; 6(11): e012773.

31. Abdollahi AA, Behnampour N, Vaghari G, et al. [The correlation between age, gender and education with obesity in urban population of Golestan Province]. Iran J Endocrinol Metab 2010; 12 (3): 276-282 [in Persian].

32. Furong $\mathrm{Xu}$, Cohen SA, Lofgren IE, et al. The association between physical activity and metabolic syndrome in older adults with obesity. J Frailty Aging 2019; 8(1): 27-32.

Tables: 4

Figures: 0

References: 32

Received: 18.06.2019

Reviewed: 21.06.2019

Accepted: 11.09.2019

Address for correspondence:

Prof. Zahra Abbaspoor

Department of Midwifery

Menopause Andropause Research Center

Ahvaz Jundishapur University of Medical Sciences

Ahvaz

Iran

Tel.: +98 9166152841

E-mail: abbaspoor_z762@yahoo.com 